\title{
Determining the Targets of Fluopsin C Action on Gram-Negative and Gram-Positive Bacteria
}

\begin{abstract}
Miguel Octavio Pérez Navarro', Guilherme Dilarri², Ane Stefano Simionato', Kathlen Grzegorczyk ${ }^{1}$, Mickely Liuti Dealis ${ }^{1}$, Barbara Gionco Cano', André Riedi Barazetti ${ }^{1}$, Leandro Afonso ${ }^{1}$, Andreas Lazaros Chryssafidis ${ }^{3}$, Henrique Ferreira ${ }^{2}$ and Galdino Andrade ${ }^{1 *}$
\end{abstract}

' Microbial Ecology Laboratory, Department of Microbiology, Universidade Estadual de Londrina, Londrina, Brazil, ${ }^{2}$ Department of Biochemistry and Microbiology, Institute of Biosciences, Universidade Estadual Paulista, Rio Claro, Brazil, ${ }^{3}$ Department of Veterinary Medicine, Center of Agroveterinary Sciences, Universidade do Estado de Santa Catarina, Lages, Brazil

The antibiotic activity of metalloantibiotic compounds has been evaluated since the $90 \mathrm{~s}$, and many different modes of action were characterized. In the last decade, the effects of secondary metabolites produced by Pseudomonas aeruginosa LV strain, including a cupric compound identified as Fluopsin C, were tested against many pathogenic bacteria strains, proving their high antibiotic activity. In the present study, the bactericidal mechanisms of action of Fluopsin $\mathrm{C}$ and the semi-purified fraction F4A were elucidated. The results found in electron microscopy [scanning electron microscopy (SEM) and transmission electronic microscopy (TEM)] demonstrated that both Fluopsin C and F4A are affecting the cytoplasmatic membrane of Gram-positive and Gram-negative bacteria. These results were confirmed by fluorescence microscopy, where these bacteria presented permeabilization of their cytoplasmatic membranes after contact with the semi-purified fraction and pure compound. Using electronic and fluorescence microscopy, along with bacterial mutant strains with marked divisional septum, the membrane was defined as the primary target of Fluopsin $\mathrm{C}$ in the tested bacteria.

\footnotetext{
Keywords: bactericidal mechanism of action, Xanthomonas, KPC, MRSA, electronic microscopy, fluorescence microscopy
}

\section{INTRODUCTION}

The development of metalloantibiotics as potential antimicrobial agents has been pursued since the 90s (Sekhon, 2010). The gene expression analysis of Pseudomonas aeruginosa LV strain cultured in the presence of copper chloride suggested that the intracellular excess of copper forms a compound with antimicrobial activity (Gionco et al., 2017). Other studies demonstrated that a specific fraction extracted from the supernatant of $P$. aeruginosa LV strain culture (F4A) presents high microbicidal activity against many pathogenic bacteria (de Oliveira et al., 2011, 2016; Cardozo et al., 2013; Murate et al., 2015; Kerbauy et al., 2016; Munhoz et al., 2017). F4A also showed strong antimicrobial effect against planktonic cells and biofilm formation of sixty-nine MDR 70 isolates, including Klebsiella pneumoniae Kpn-19 (Kerbauy et al., 2016). One of the main bioactive compounds produced by $P$. aeruginosa LV strain is a metalloantibiotic (organocopper compound), which is promising to become a new antibiotic in the control of infections caused by 
MDR bacteria. This metalloantibiotic was identified as Fluopsin C (YC 73), and it is a secondary metabolite produced by Pseudomonas spp. and Streptomyces sp., with high antibacterial, antifungal, and antitumor activities (Itoh et al., 1970; Otsuka et al., 1972; Ma et al., 2013). However, little is known about the mechanisms of action of Fluopsin C on Gram-negative and Gram-positive bacteria.

In previous studies, it was observed that pathogenic bacteria treated with the semi-purified fraction F4A fraction or Fluopsin $\mathrm{C}$ presented complete disruption of cell membrane and frequent presence of cells that stopped septation (Vasconcellos et al., 2014; Murate et al., 2015; de Oliveira et al., 2016; Kerbauy et al., 2016; Munhoz et al., 2017; Navarro et al., 2019). However, to the best of our knowledge, the major mechanism of action of these compounds has not yet been defined. The determination of the mechanisms of action of an antimicrobial compound is essential for defining how the bacterial damage happens, and which possible mechanisms of resistance may arise in the future.
Another advantage is the determination of the time needed by the antimicrobial agent to inhibit bacterial development, depending on the mechanism of action.

Therefore, the objective of this study was to determine the action target of Fluopsin C using Xanthomonas citri subsp. citri and Klebsiella pneumoniae Kpn-19 as Gram-negative models and Staphylococcus aureus ATCC 29213 and Enterococcus faecium ATCC 6569 as Gram-positive bacteria.

\section{MATERIALS AND METHODS}

\section{Bacterial Strain and Growth Conditions}

Xanthomonas citri subsp. citri strain (Xcc) used for the membrane integrity analyses was the isolate 306 (IBSBF 1594) (Schaad et al., 2006). The mutant strain $X$. citri amy:pPM2a-zapA, expressing GFP-ZapA that labels the divisional septum, was used to investigate the interference on bacterial cell division
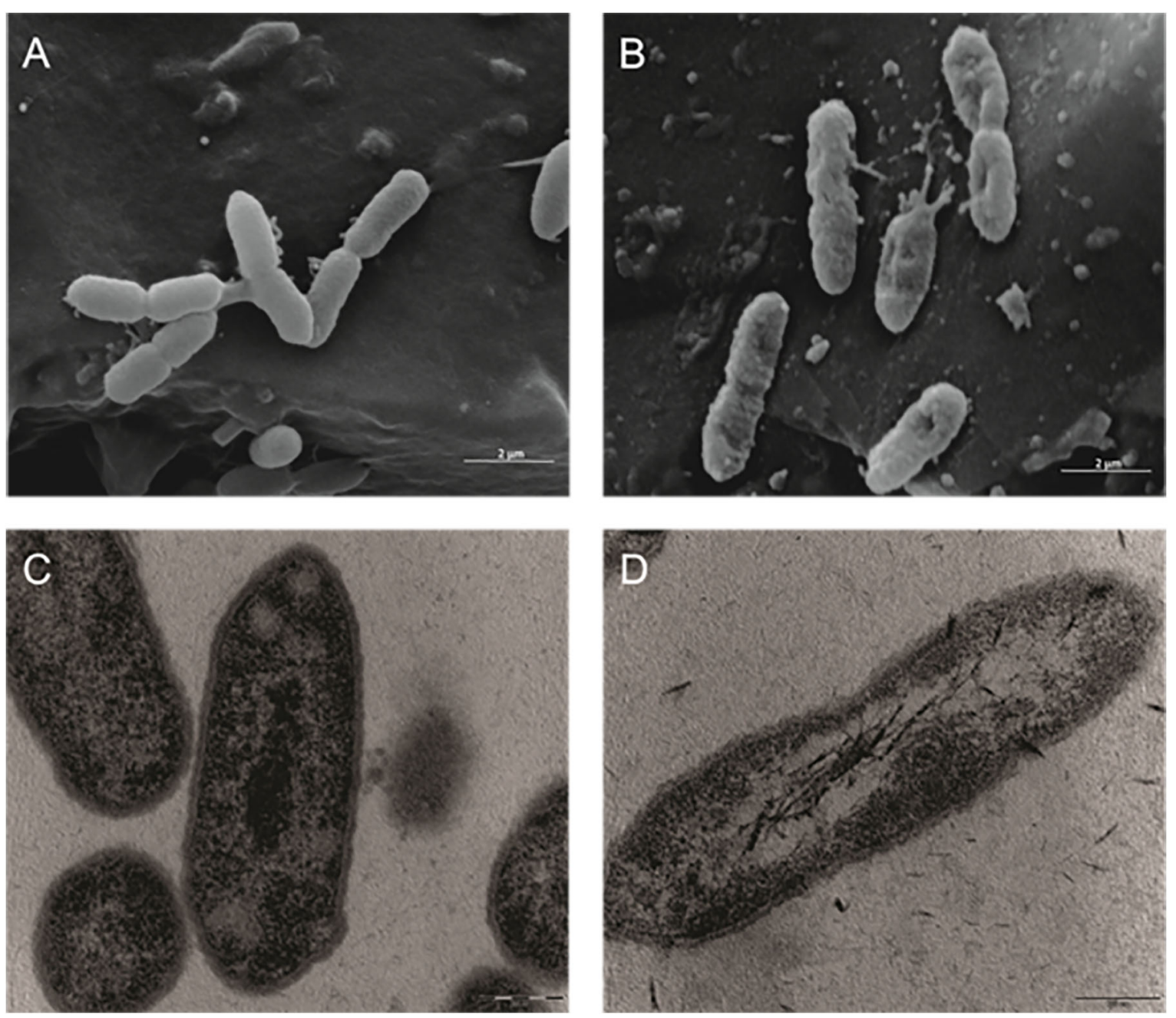

FIGURE 1 | Effect of the F4A fraction on the ultra-structure of the Gram-negative bacteria Xanthomonas citri subsp. citri, strain 306 strain. Scanning electron microscopy: (A) control (non-treated) (20,000x); (B) cells treated with F4A fraction $(20,000 \times)$. Transmission electron microscopy (C) control (non-treated) (46,000x); (D) cells treated with F4A fraction (46,000). 
(Martins et al., 2010). Both X. citri strains were cultivated in NYG/NYG-agar medium (nitrogen-yeast-glycerol: $5 \mathrm{~g} / \mathrm{L}$ of peptone, $3 \mathrm{~g} / \mathrm{L}$ of yeast extract, $2 \%$ glycerol; for solid medium bacterial agar was added to $15 \mathrm{~g} / \mathrm{L}$ ) at $28^{\circ} \mathrm{C}$ for $24 \mathrm{~h}$, in and orbital shaker at $200 \mathrm{rpm}$. K. pneumoniae Kpn-19 was isolated from patients attended at the University Hospital of Londrina, PR, Brazil, and it is deposited at the microbial collection of Microbiology Laboratory of the same hospital (Kerbauy et al., 2016). K. pneumoniae Kpn-19, E. faecium ATCC 6569, and S. aureus ATCC 29213, were cultured in $\mathrm{MH} / \mathrm{MH}$ (MüellerHilton medium) at $37^{\circ} \mathrm{C}$.

\section{Effect of F4A Fraction and Fluopsin C on the Ultra-Structure of Gram-Negative and Gram-Positive Bacteria}

The F4A fraction and Fluopsin $\mathrm{C}$ used in this study were obtained according to procedures described by Munhoz et al. (2017) and Navarro et al. (2019), respectively. The F4A contains basically four compounds (mg/L): phenazine-1-carboxylic acid (14 mg), phenazine-carboxamide (9 mg), indol-3-one (1 mg), and Fluopsin C (6 mg) (Bedoya et al., 2019). IC 90 was used in the following assays for enhancing the analyses. The majority of dead bacteria reflect the antibiotic effect of the tested compounds, but the remaining organisms present different stages of cell destruction, allowing the detailed observation of their mechanisms of action. For the scanning electron microscopy assay (SEM), bacterial suspensions $\left(10^{10} \mathrm{CFU}\right)$ of each strain were incubated for $60 \mathrm{~min}$ with and without $\mathrm{IC}_{90}$ concentrations of F4A (0.25 $\mu \mathrm{g} \mathrm{mL}^{-1}$ for $X$. citri) (Murate et al., 2015) and Fluopsin C (2 $\mathrm{g} \mathrm{m} \mathrm{mL}^{-1}$ for $K$. pneumoniae, $1 \mu \mathrm{g} \mathrm{mL} \mathrm{m}^{-1}$ for E. faecium, and $0.5 \mu \mathrm{g} \mathrm{mL} \mathrm{m}^{-1}$ for $S$. aureus) (Navarro et al., 2019) were spotted onto poly-L-lysine-coated slides and stored at $28^{\circ} \mathrm{C}$ for $1 \mathrm{~h}$ for drying. The slides were fixed with a solution containing 2\% paraformaldehyde and 2.5\% glutaraldehyde in $0.1 \mathrm{M}$ sodium cacodylate buffer $(\mathrm{pH} 7.0$ ) for $12 \mathrm{~h}$. After that,
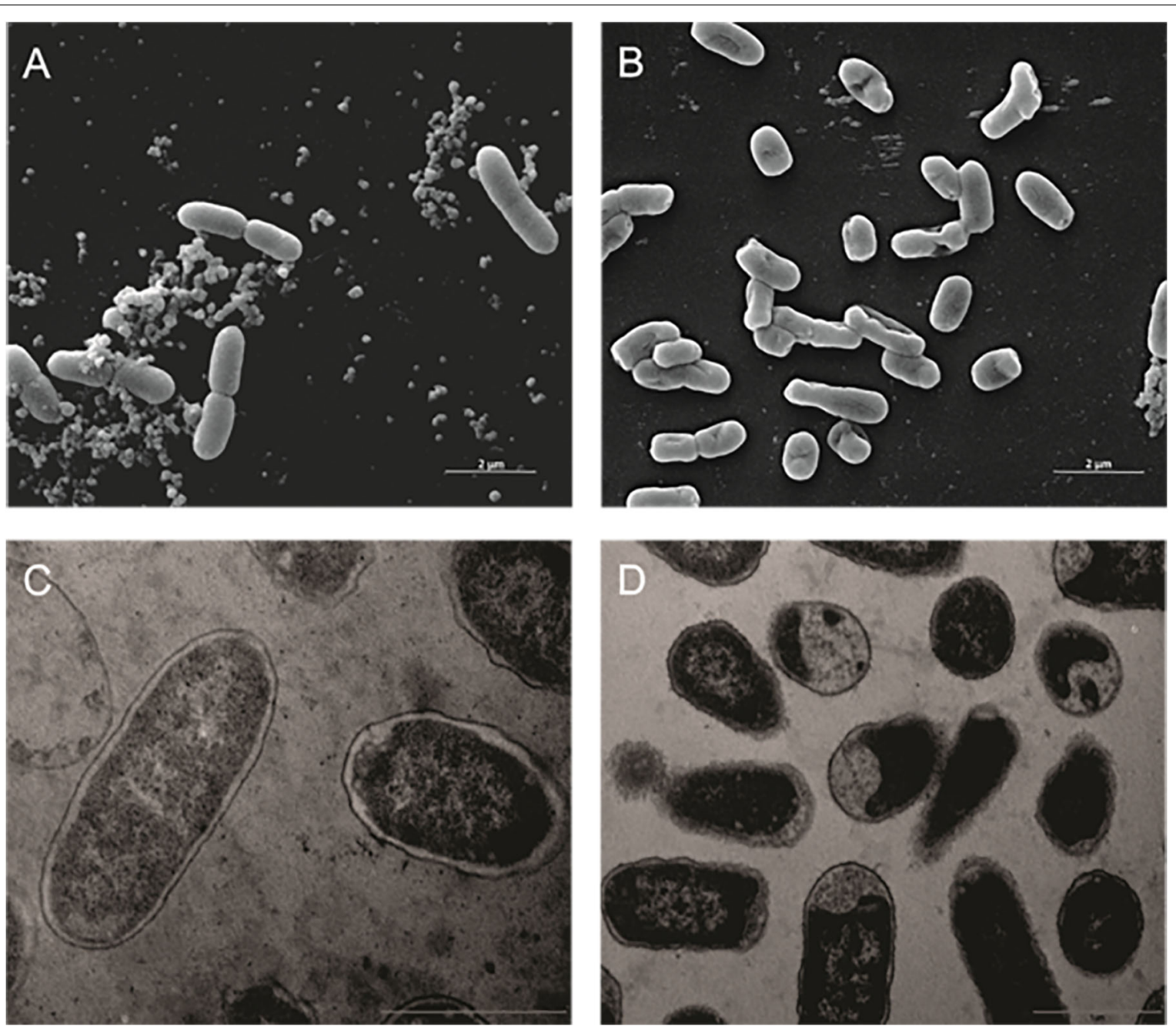

FIGURE 2 | Effect of the antibiotic activity of Fluopsin C on the ultra-structure of the Gram-negative bacteria Klebsiella pneumoniae Kpn-19. Scanning electron microscopy: (A) control (non-treated) $(10,000 \times)$; (B) cells treated with Fluopsin C (10,000x). Transmission electron microscopy (C) control (non-treated) (26,500x); (D) cells treated with Fluopsin C $(18,500 \times)$. 
the slides were washed with $0.1 \mathrm{M}$ sodium cacodylate buffer $\left(\mathrm{pH} 7.0\right.$ ) and post-fixed in a solution of $1 \% \mathrm{OsO}_{4}$ for $2 \mathrm{~h}$. The samples were dehydrated in ethanol at concentrations of 70, 80, 90, and $100 \%$ and then dried by critical point in $\mathrm{CO}_{2}$ (BALTEC CPD 030 Critical Point Dryer). After drying, the slides were coated with gold (BALTEC SDC 050 Sputter Coater) and visualized under a scanning electron microscope (FEI Quanta 200).

For the transmission electronic microscopy (TEM) assay, microorganisms were incubated with and without $\mathrm{IC}_{90}$ concentrations of F4A $\left(0.25 \mu \mathrm{g} \mathrm{mL} \mathrm{m}^{-1}\right.$ for X. citri 306) and Fluopsin C (2 $\mu \mathrm{g} \mathrm{mL}^{-1}$ for K. pneumoniae and $0.5 \mu \mathrm{g} \mathrm{mL}^{-1}$ for $S$. aureus). The samples were centrifuged at 4,000 rpm for $5 \mathrm{~min}$. The pellets were resuspended, washed with PBS, centrifuged again, and fixed as described above. After dehydration in a series of ethanol, the material was included in Araldite. Ultra-thin cuts of 60-70 nm (Leica ULTRACUT Ultramicrotome) were made in the block and contrasted with $2 \%$ uranyl acetate for $15 \mathrm{~min}$ and lead citrate for 20 min and observed under the transmission electron microscope (FEI Tecnai 12).

\section{Membrane Permeability and Cell Division Disruption Assays}

Cells of E. faecium, S. aureus, and X. citri $\left(10^{5} \mathrm{CFU}\right)$ were incubated in $0.1 \mathrm{~mL}$ of the respective culture medium for 15 min containing $\mathrm{IC}_{90}$ concentrations of F4A $\left(0.25 \mu \mathrm{g} \mathrm{mL}^{-1}\right.$ for $X$. citri) and Fluopsin $\mathrm{C}\left(1 \mu \mathrm{g} \mathrm{mL}^{-1}\right.$ for E. faecium and $0.5 \mu \mathrm{g} \mathrm{mL}^{-1}$ for $S$. aureus). Right after this incubation period, $0.9 \mathrm{~mL}$ of each respective culture medium was added to the reaction tubes in order to stop the treatments. Tubes were centrifuged at $3,000 \times g$ for $30 \mathrm{~s}$, the supernatant was discarded, and the cells were resuspended in $100 \mu \mathrm{L}$ of sterile saline $(0.9 \% \mathrm{NaCl})$. Membrane integrity was verified by staining the cells with DAPI and propidium iodide (IP), according to the manufacturer instructions (LIVE/DEAD
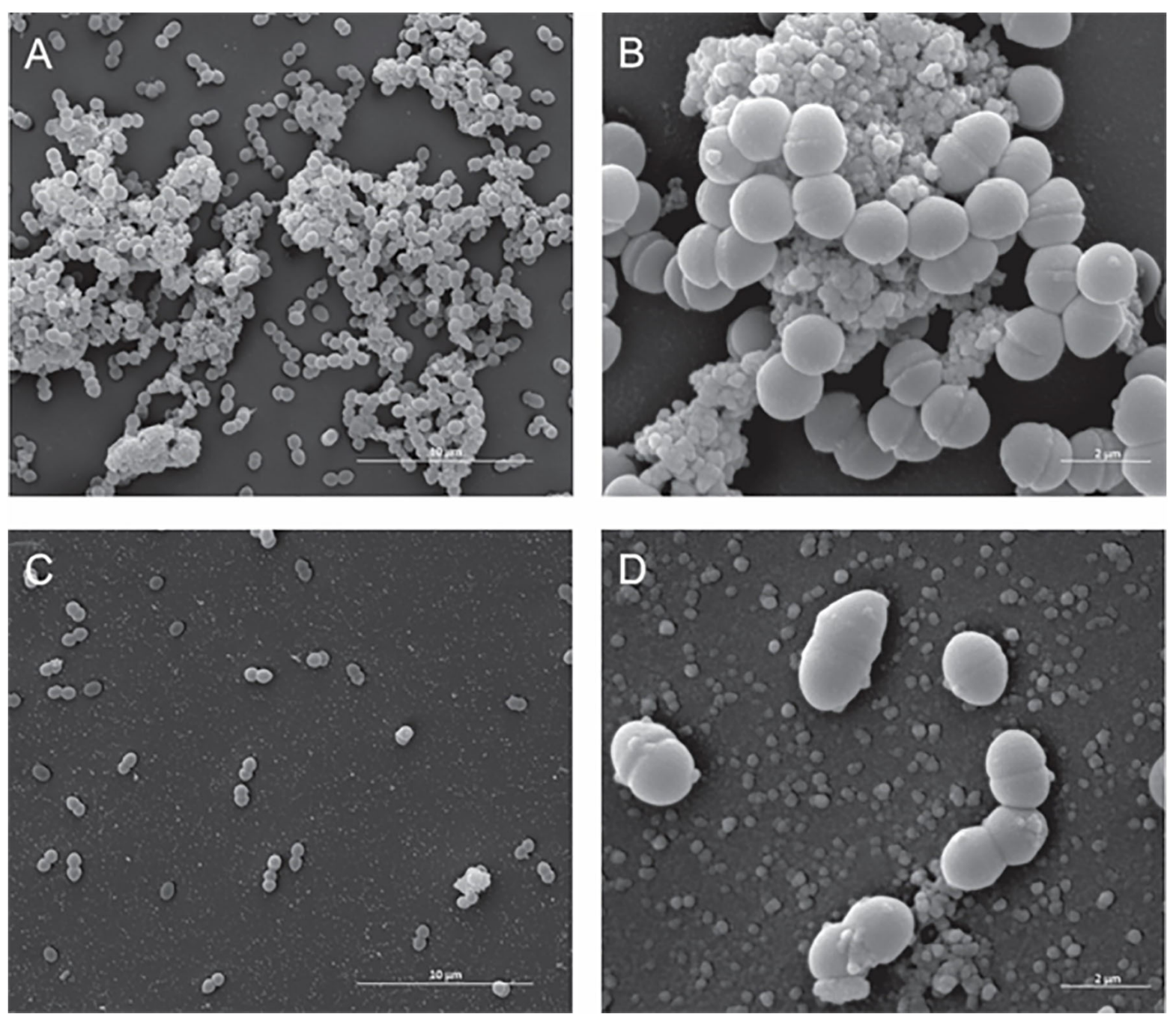

FIGURE 3 | Effect of the antibiotic activity of Fluopsin C on the ultra-structural of the Gram-positive bacteria Enterococcus faecium strain ATCC 6569. Scanning electron microscopy: (A,B) control (non-treated) - (A) 8,000x and (B) $(40,000 \times)$; (C,D) cells treated with Fluopsin C - (C) $(8,000 \times)$ and (D) $(40,000 \times)$. 
BacLight Bacterial Viability Kit; Thermo Fisher Scientific L7012). DAPI (4',6-diamidino-2-phenylin-dole) is a DNA-specific probe, a fluorescent dye that naturally enters the cells, regardless of whether they are alive or with corrupted membranes. DAPI stains the genetic material/bacterial nucleoid (Kapuscinski, 1995). With the nucleoid stained, it is possible to observe any anomalous segregation of the bacterial chromosome before or after cell division. Ten microliter of each cell suspension was placed on microscope slides covered with $1 \%$ agarose in saline for microscopic observation (Martins et al., 2010). To generate the positive controls for membrane permeability, $X$. citri cells were heated for $2 \mathrm{~min}$ at $55^{\circ} \mathrm{C}$ (Sumares et al., 2016; Savietto et al., 2018), and Gram-positive bacteria were exposed to Nisin (SIGMA N5764) (Król et al., 2015). DAPI labeling was also applied to investigate possible chromosome segregation defects, such as misplaced bacterial nucleoids, and the presence of anucleated cells.

For evaluating cell division, $100 \mu \mathrm{L}$ of $X$. citri amy:pPM2a-zapA culture, containing $10^{5}$ cells, were treated with
F4A or fluopsin C at their IC90 concentration $\left(0.25 \mu \mathrm{g} \mathrm{mL}^{-1}\right.$ for both compounds) or 1\% DMSO (vehicle control) for $15 \mathrm{~min}$ at $30^{\circ} \mathrm{C}$. After the incubation period, the volume was increased to $1 \mathrm{~mL}$ to stop the reaction, and tubes were centrifuged at $3,000 \times g$ for $30 \mathrm{~s}$. The supernatant was discarded, and cells were resuspended with $100 \mu \mathrm{L}$ of sterile saline $(0.9 \% \mathrm{NaCl})$. Ten microliter of the cell suspension was put onto slides covered with $1 \%$ agarose $1 \%$ in saline for microscopic observation (Martins et al., 2010).

All samples were examined by fluorescence microscopy using an Olympus BX-61 optical microscope, equipped with a Fluorescence UIS2 optical system (DAPI excitation $372 \mathrm{~nm} / \mathrm{emission} 456 \mathrm{~nm}$; Tx red excitation $596 \mathrm{~nm} /$ emission $620 \mathrm{~nm}$; GFP excitation $475 \mathrm{~nm} /$ emission $509 \mathrm{~nm})$. Images were captured using a monochromatic camera Orca-Flash 2.8 (Hamamatsu, Japan), with the software CellSens v. 11 (Olympus). All the experiments were performed in triplicates with a minimum of $n=200$ cells per experiment.
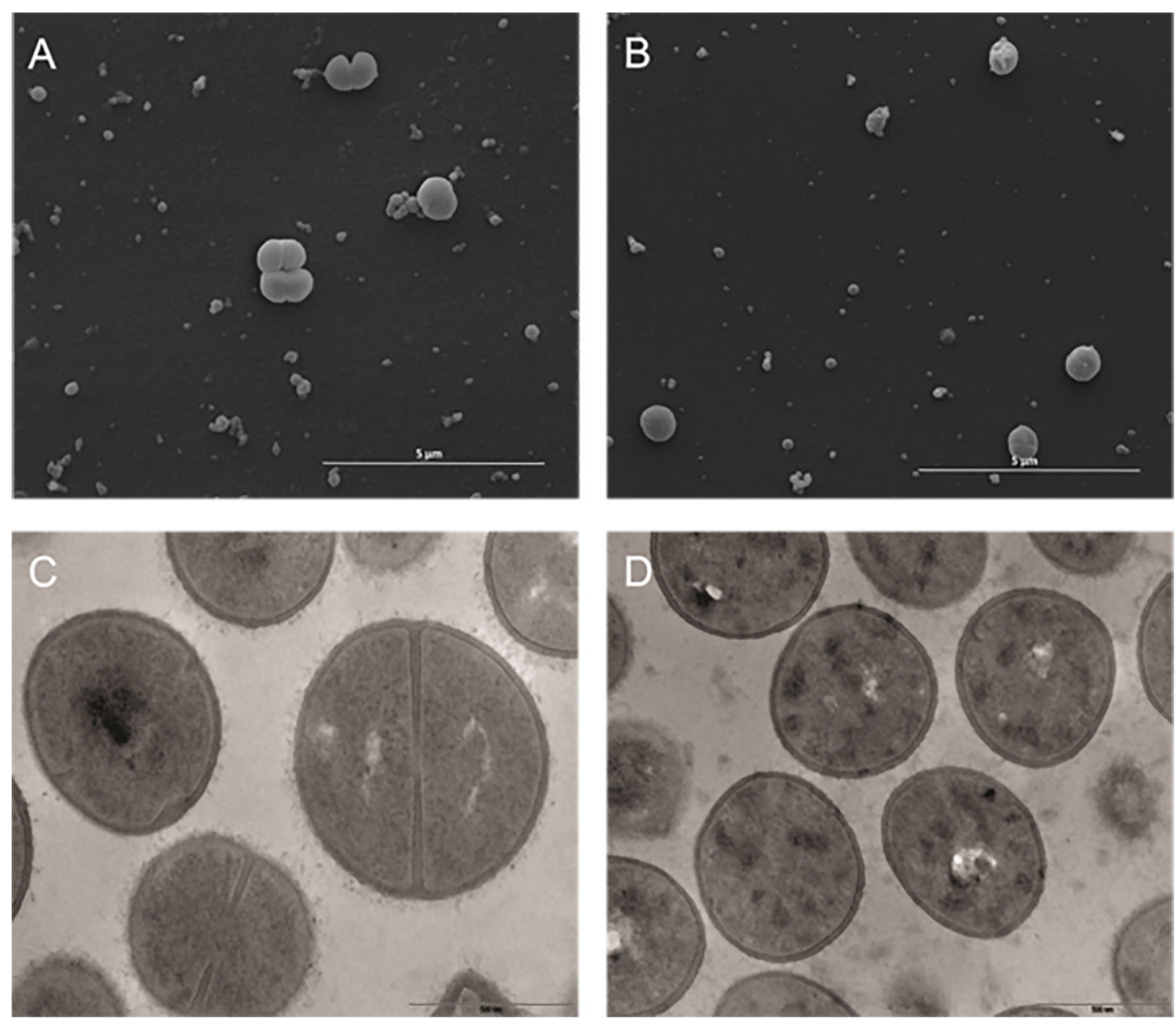

FIGURE 4 | Effect of the antibiotic activity of Fluopsin C on the Gram-positive bacteria Staphylococcus aureus strain MRSA N315. Scanning electron microscopy: (A) control (non-treated) (10,000x); (B) cells treated with fluopsin $(10,000 \times)$ (46,000x). Transmission electron microscopy (C) control (non-treated) (46,000 x); (D) cells treated with Fluopsin C (37,000x). 

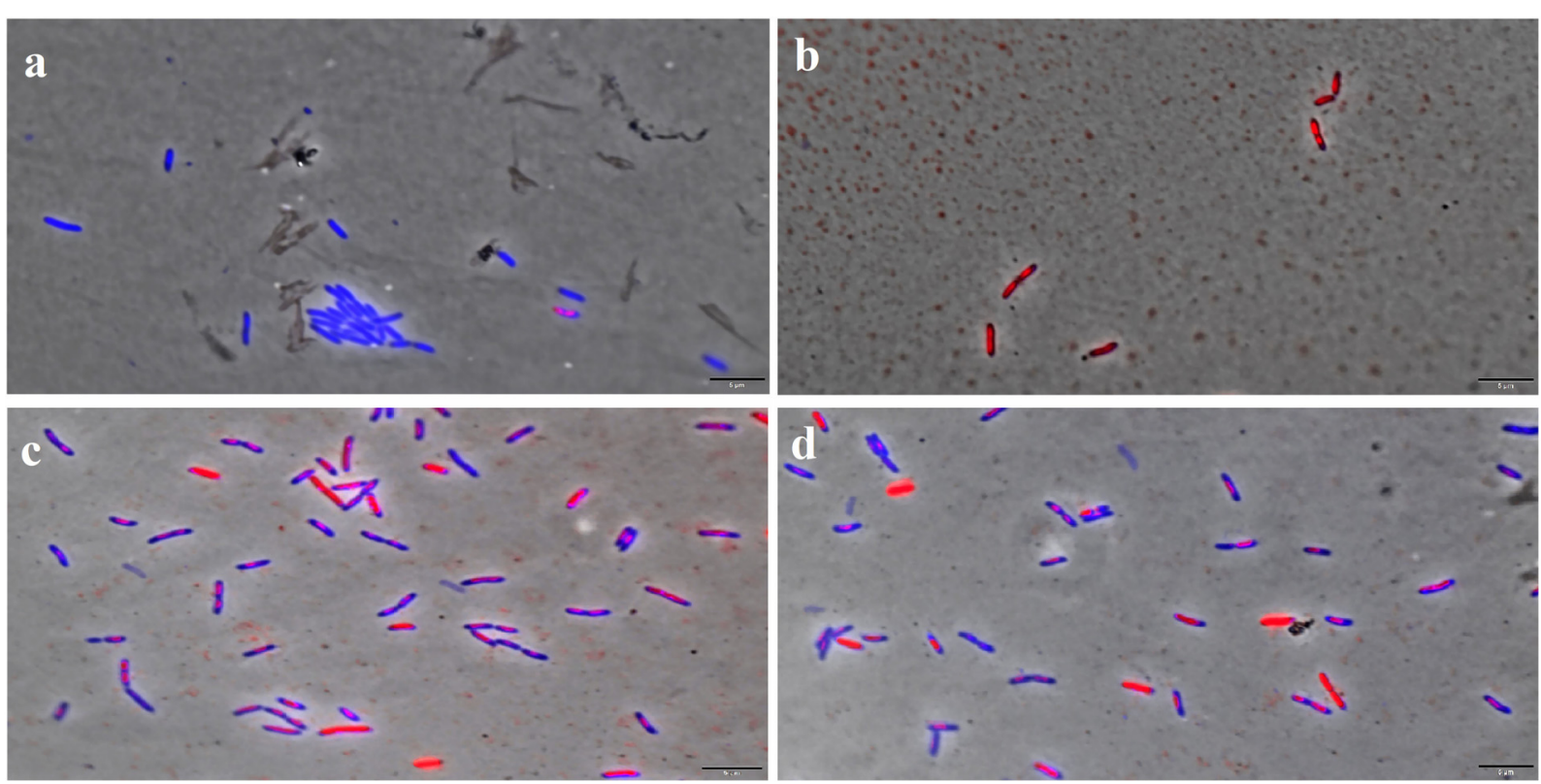

FIGURE 5 | F4A and Fluopsin C permeabilized the membrane of $X$. citri subsp. citri strain 306. Cells were exposed to the compounds at their respective IC 90 values for 15 min and stained with DAPI/IP before microscope observation. Cells with intact membrane are shown in blue, while cells with disrupted membrane are in red.

(A) non-treated cells; (B) positive control, cells with membrane permeabilized by temperature stress; (C) cells treated with Fluopsin C; (D) cells treated with F4A fraction. Images are the overlay of phase-contrast microscopy and fluorescence. The filters Tx Red and DAPI Blue were applied together and used to visualize IP and DAPI. The bars correspond to $5 \mu \mathrm{m}$; magnification of $100 \mathrm{X}$.
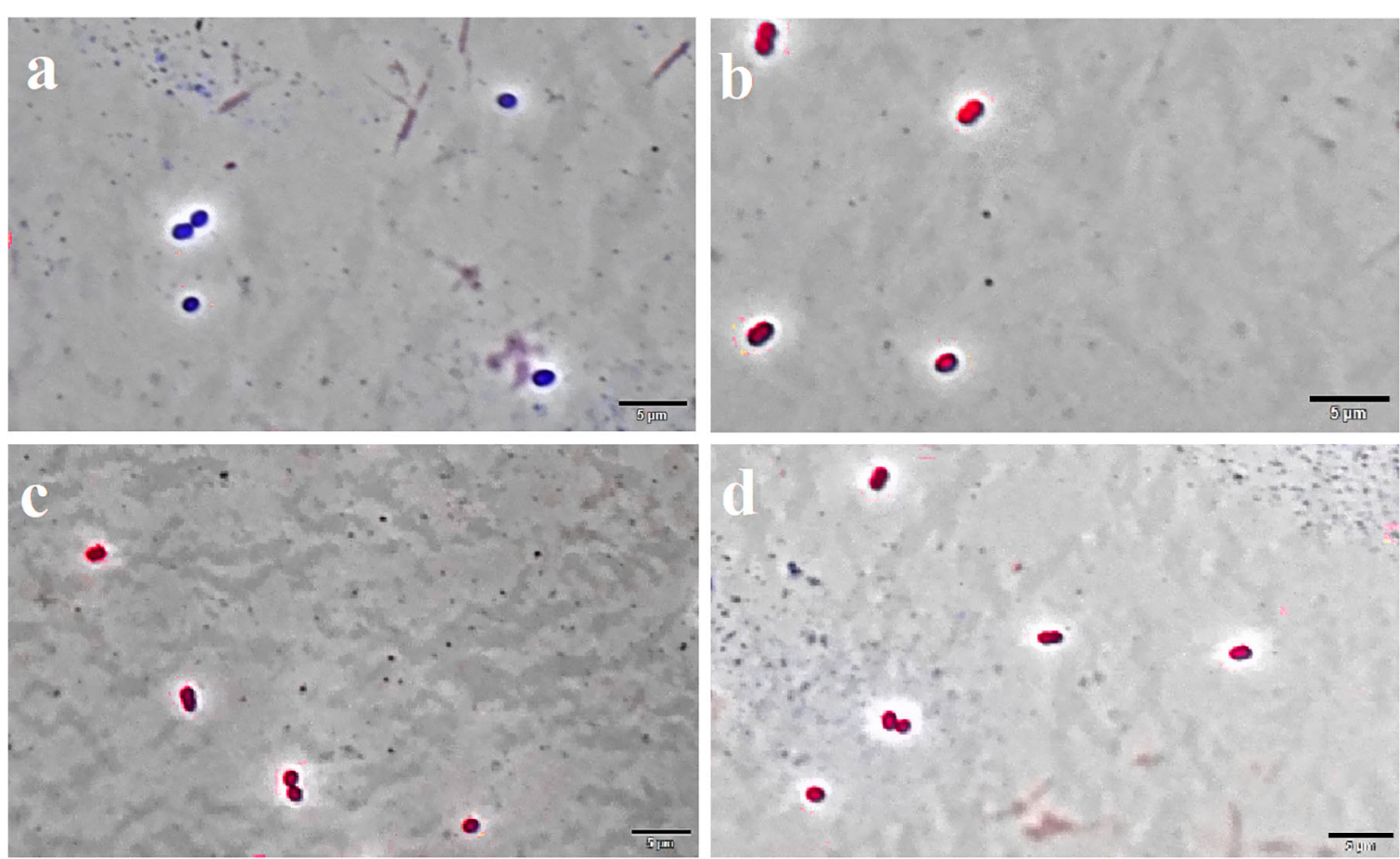

FIGURE 6 | F4A and Fluopsin C permeabilized the membrane of E. faecium ATCC 6569. Cells were exposed to the compounds at their respective IC 90 values for $15 \mathrm{~min}$, and after staining with DAPI/IP before microscope observation. Cells with intact membrane are shown in blue, while cells with disrupted membrane are in red. (A) non-treated cells; (B) positive control, cells treated with nisin at $2.5 \mu \mathrm{g} / \mathrm{mL}$; (C) cells treated with Fluopsin C; (D) cells treated with F4A fraction. Images are the overlay of phase-contrast microscopy and fluorescence. The filters Tx Red and DAPI Blue were applied together and used to visualize IP and DAPI. The bars correspond to $5 \mu \mathrm{m}$; magnification of $100 \mathrm{X}$. 

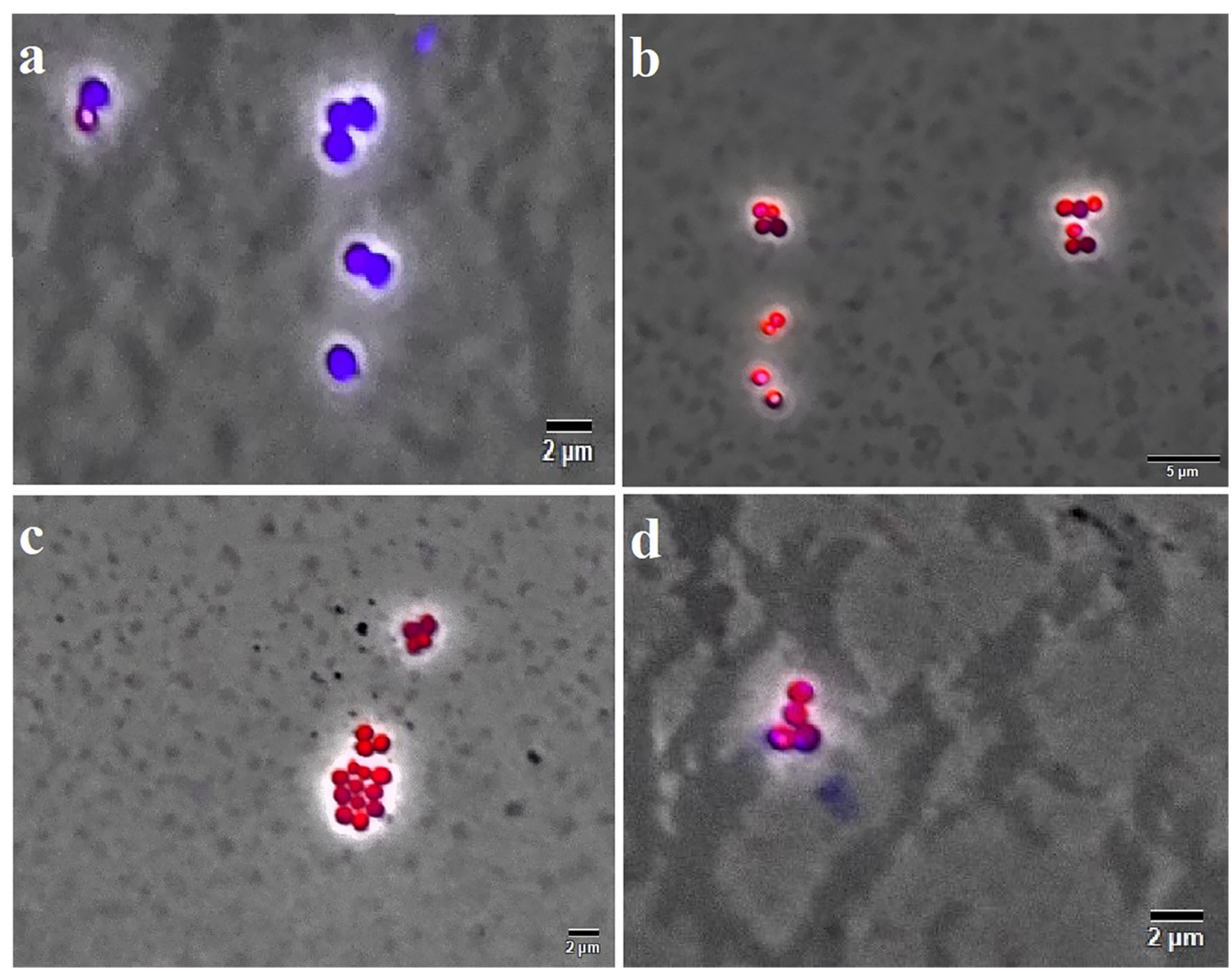

FIGURE 7 | F4A and Fluopsin C permeabilized the membrane of S. aureus strain ATCC 29213. Cells were exposed to the compounds at their respective IC90 values for $15 \mathrm{~min}$, and after staining with DAPI/IP before microscope observation. Cells with intact membrane are shown in blue, while cells with disrupted membrane are in red. (A) non-treated cells; (B) positive control, cells treated with nisin at $2.5 \mu \mathrm{g} / \mathrm{mL}$; (C) cells treated with Fluopsin C; (D) cells treated with F4A fraction. Images are the overlay of phase-contrast microscopy and fluorescence. The filters Tx Red and DAPI Blue were applied together and used to visualize IP and DAPI. The bars correspond to $5 \mu \mathrm{m}$; magnification of 100X.

\section{RESULTS}

\section{Effect of F4A Fraction and Fluopsin C on the Ultra-Structure of Gram-Negative and Gram-Positive Bacteria}

Both the SEM analysis revealed that untreated $X$. citri subsp. citri 306 strain cells did not present any morphological changes (Figure 1A) when compared to the treated cells, where Fluopsin $\mathrm{C}$ disrupted the membrane and cells appeared shrunken and rough compared to the control (Figure 1B). At the TEM, it was observed that the cell wall and the cytoplasmic membrane of nontreated $X$. citri appeared to be intact (Figure 1C), while treated cells presented modified cell shape and morphology (Figure 1D), being elongated and with affected cell wall and cytoplasmic membrane, becoming indistinct.

The same alterations in cell ultra-structure were observed in other Gram-negative bacteria. In the SEM, K. pneumoniae Kpn-19 strain control cells were intact (Figure 2A) and treated cells had their cell membranes and walls disrupted (Figure 2B).
Similar effects were observed by TEM, where the control cells were intact (Figure 2C) and treated cells presented significant changes in the cell membrane and wall, as well as in the cytoplasm (Figure 2D).

With Gram-positive bacteria, SEM analysis did not unveil marked differences between treated and untreated Enterococcus faecalis ATCC 6569 strain cells (Figures 3A,B), but the number of cells decreased severely when Fluopsin C was present (Figures 3C,D).

On the other hand, S. aureus MRSA N315 strain-treated cells had overt changes in their cell membrane and wall when compared with the controls (Figures 4A,B). Fluopsin C exposed cells apparently lost their cell wall and presented heterogeneous and electron dense cytoplasm when compared to untreated cells (Figures 4C,D).

\section{Membrane Permeability Assay}

The Live/Dead test showed that F4A fraction and Fluopsin $\mathrm{C}$ affected the cell membrane of $X$. citri after $15 \mathrm{~min}$ of 


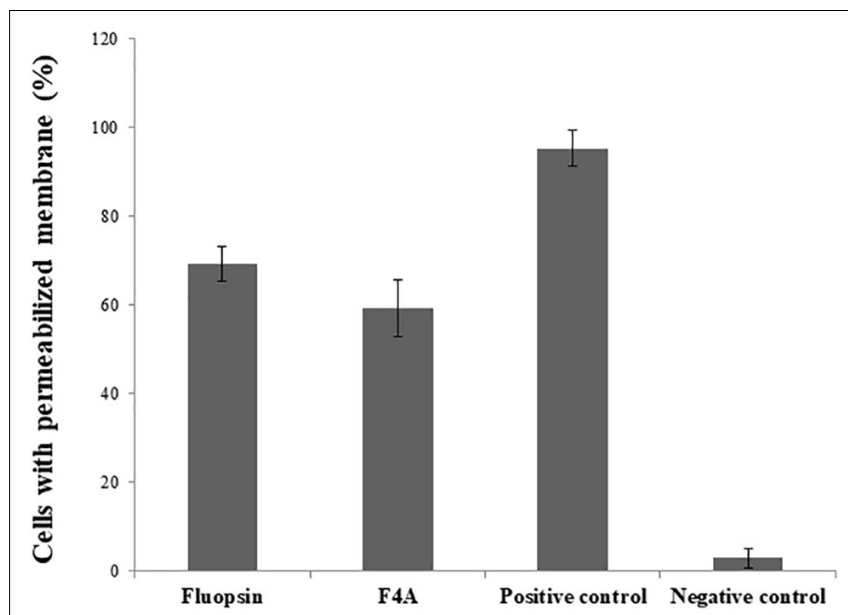

FIGURE 8 | Percentage of Xanthomonas citri subsp. citri cells with permeabilized membrane caused by the exposure to F4A and fluopsin. Negative control consists of untreated cells, and positive control consists of cells permeabilized by heat stress. exposure, causing serious damage and increasing its permeability (Figure 5). The F4A fraction and Fluopsin $\mathrm{C}$ also affected the cell membranes of E. faecium ATCC 6569 (Figure 6) and S. aureus ATCC 29213 (Figure 7), as reflected by the increased permeability to the nucleoid dye propidium IP compared to the control untreated.

No difference was observed in the activities of both F4A and Fluopsin C, where approximately $60 \%$ of $X$. citri cells presented a similar extent of membrane disruption when compared to the positive control (heat shock; Figure 8). The results demonstrate that the cell membrane is one of the targets of F4A and Fluopsin C.

There was little difference in the number of cells with disrupted membrane treated with F4A and Fluopsin C. Both compounds affected more than 70\% of the E. faecium ATCC 6569 and S. aureus ATCC 29213 cells (Figure 9), and results were very close to the positive control (treated with Nisin). Therefore, the results suggested that the plasmatic membrane is one of the targets of F4A and Fluopsin C for E. faecium ATCC 6569 and S. aureus ATCC 29213 as well. F4A and Fluopsin C were more effective against $S$. aureus ATCC 29213, with very similar results to the cells treated with Nisin.

\section{Evaluation of Cell Septum Disruption Analyses}

The mutant strain $X$. citri amy:pPM2a-zapA, labeled for the divisional septum, when treated with F4A or Fluopsin $\mathrm{C}$, indicated that both compounds can affect the cellular division by interfering in the Z-ring of $X$. citri (Figure 10). Untreated $X$. citri amy:pPM2a-zapA displays a fluorescent bar, the Z-ring, perpendicular to the long axis of the rods for the cells that are preparing to divide (Figure 10A). After exposure to both compounds for $15 \mathrm{~min}$, the Z-ring was completely dissolved and could not be detected any

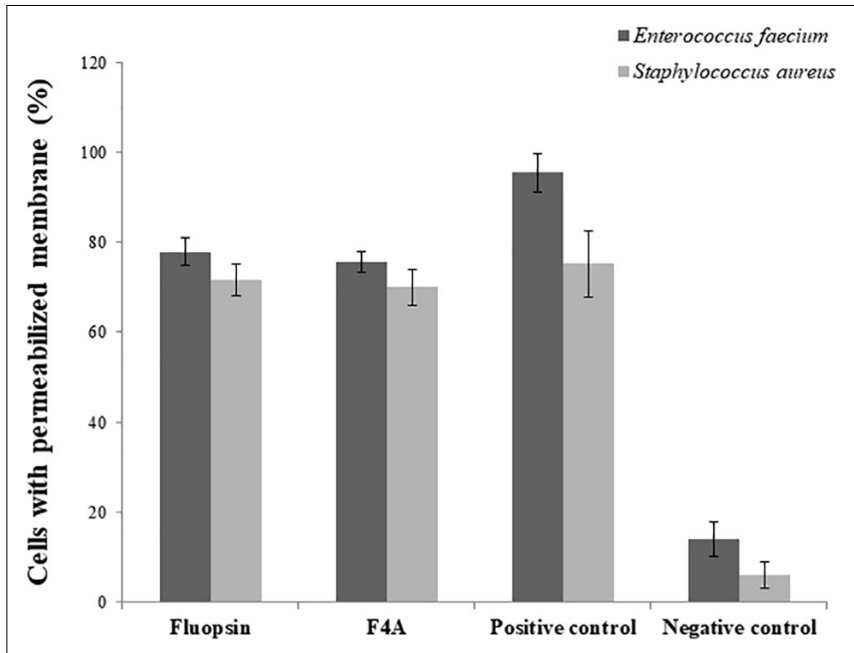

FIGURE 9 | Percentage of Enterococcus faecium ATCC 6569 and Staphylococcus aureus ATCC 29213 cells with permeabilized membrane caused by the exposure to F4A and fluopsin. Negative control consists of untreated cells, and positive control consists of cells permeabilized by nisin.

longer (Figures 10B,C). However, subsequent morphological examination of wild-type $X$. citri by phase-contrast microscopy, and analysis of nucleoid distribution using DAPI, did not evidence any increase in the number of abnormal cells, i.e., filaments and cells with increased size, minicells, and dividing cells showing septal constriction and continuous nucleoid at the same time $(p<0.5)$ (Figure 11). X. citri did not show any increase in cell size after treatment with F4A or Fluopsin C (Table 1).

\section{DISCUSSION}

F4A and Fluopsin C generated the same effect on Xcc 306 that was observed earlier by de Oliveira et al. (2011), where the cell membrane and wall were completely disrupted. The same action was observed in Kpn-19 strain treated with Fluopsin C (Navarro et al., 2019), suggesting that the compound acts in the same way in different Gram-negative genera.

Additionally, the antibiotic activity of Fluopsin $\mathrm{C}$ was tested in two different genera of Gram-positive bacteria, but the effects on cell ultrastructural were not the same in E. faecium ATCC 6569 and MRSA N315. In E. faecium ATCC 6569 strain, despite the decrease in cell numbers after treatment with Fluopsin C, no damage was detected in its cell membrane and wall. On the other hand, treated MRSA N315 strain bacteria presented the same changes on cell membrane and wall that was observed in Gram-negative bacteria, with cell disruption and changes in the cytoplasm. Similar activity was reported previously (Navarro et al., 2019).

Different authors observed the effect of F4A on cell morphology by scanning and transmission electron microscopy of X. citri subsp. citri (de Oliveira et al., 2011), other Gramnegative bacteria (Lopes et al., 2012; Murate et al., 2015; 

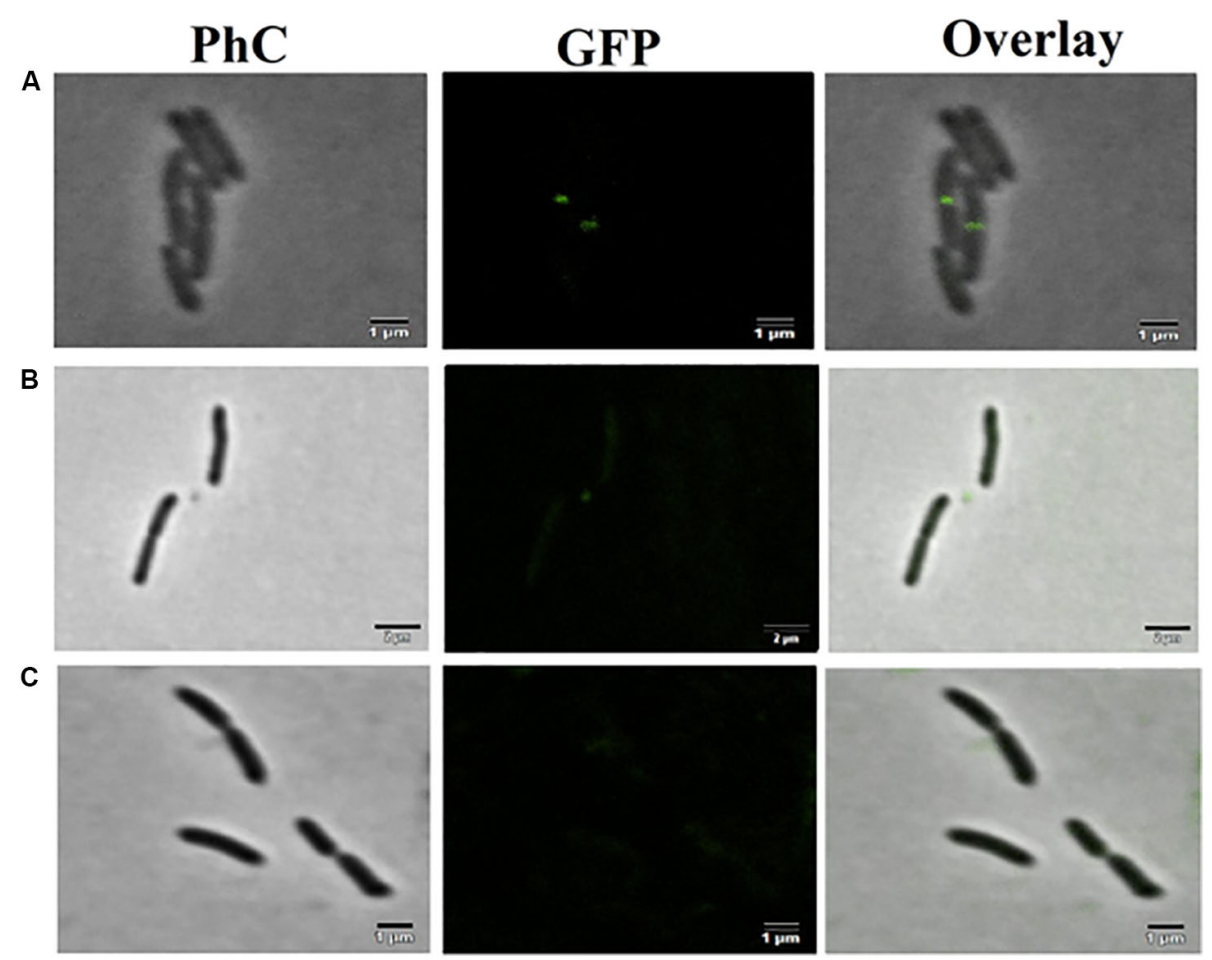

FIGURE 10 | F4A and fluopsin perturbed the divisional septum of $X$. citri. The mutant strain $X$. citri amy:pPM2a-zapA, labeled for the divisional septum, was exposed to F4A or fluopsin at their $\mathrm{IC}_{90}$ values for $15 \mathrm{~min}$, and after being analyzed by fluorescent microscopy. (A) untreated control; (B) cells treated with fluopsin; (C) cells treated with F4A. The divisional septum corresponds to the green bar perpendicular to the long axis of the rods. The bar corresponds to $1 \mu \mathrm{m}$; magnification of $100 \mathrm{X}$

Kerbauy et al., 2016; Munhoz et al., 2017), and Gram-positive bacteria (Cardozo et al., 2013). In the present study, the complete disruption of the cell membrane was verified after

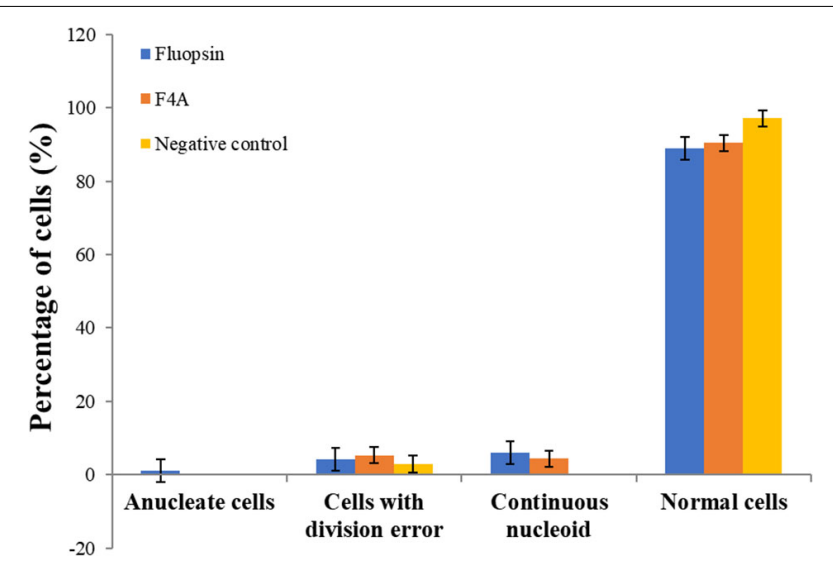

FIGURE 11 | F4A and Fluopsin C did not interfere with chromosome segregation and cell division in $X$. citri. Cells of $X$. citri were exposed to F4A or Fluopsin $\mathrm{C}$ at their $\mathrm{IC}_{90}$ values for $15 \mathrm{~min}$ and stained with DAPI before microscope observation. The percentage of cells showing division and chromosome segregations errors, such as filamentation, anucleate cells, and/or continuous nucleoid were determined by comparison with the negative control (untreated cells). Experiments were performed in triplicate (200 cells were analyzed per experiment; $n=200$ ).
15 min of exposure to F4A. Also, cells remained attached during duplication (de Oliveira et al., 2011), suggesting that F4A may inhibit the cell septation process.

Fluopsin $\mathrm{C}$ pure or present in F4A fraction inhibited $E$. faecium ATCC 6569 and S. aureus ATCC 29213 due to the disarrangement of cell membrane structure, leading both strains to death after $15 \mathrm{~min}$ of treatment, suggesting that both compounds also act on the cell membrane structure of Grampositive bacteria; this result corroborated and clarified the findings of Navarro et al. (2019).

The compounds did not impair significantly in the cell division process, as there was no disarrange in the genetic material or in the chromosomal segregation process. However, F4A and Fluopsin $\mathrm{C}$ were able to disrupt $X$. citri divisional septum. This effect was probably secondary to the breakdown of the membrane potential. The membrane potential is required to keep FtsZ protein in the correct localization on the membrane,

TABLE 1 | Morphological analyses of cell size of $X$. citri subsp. citri.

\begin{tabular}{lcccc}
\hline & Longer cell $(\mu \mathbf{m})$ & Shorter cell $(\mu \mathbf{m})$ & Mean $(\mu \mathbf{m})$ & * \\
\hline Negative control & 3.45 & 1.05 & 1.66 & - \\
F4A & 3.30 & 0.96 & 1.80 & n.s. \\
Fluopsin & 3.80 & 0.95 & 1.90 & n.s. \\
\hline
\end{tabular}

*Means of hundred cells. Non-significant (n.s.) $(p<0.5)$ when compared with treated cells and non-treated cells. 
and it corroborates the observed effect (Strahl and Hamoen, 2010). It is possible to conclude that the primary target of Fluopsin $\mathrm{C}$ is the cell membrane, and the divisional septum becomes delocalized because of the interference with the membrane potential. Other targets may be involved, and further studies should be carried out.

\section{CONCLUSION}

Electronic microscopic analysis demonstrated that F4A and Fluopsin $\mathrm{C}$ are affecting the cytoplasmatic membrane of Gram-positive and Gram-negative bacteria used in this study. This corroborates with the results of fluorescence microscopy, where Gram-positive and Gramnegative bacteria presented permeabilization of their cytoplasmatic membranes after contact with F4A and Fluopsin C.

The experiment using the mutant $X$. citri amy:pPM2a$z a p A$ showed that the divisional ring is affected by both antimicrobial compounds, but it was concluded that this is a secondary effect. The cytoplasmatic membrane damage leads to dissolution of the divisional septum, by the disturbance of the cellular membrane potential. Morphological analysis of the cells also confirmed it, since the treatment with the antimicrobial compounds did not lead to any significant increase in the number of aberrant cells. Overall, it can be concluded that the cytoplasmatic membrane is the primary target of F4A and Fluopsin C.

The effect on cell septation was not completely understood, and further studies need to be carried out. The cells may pause the division process many times, especially in Gram-negative bacteria, but it was also observed in $S$. aureus.

\section{REFERENCES}

Bedoya, J. C., Dealis, M. L., Silva, C. S., Niekawa, E. T. G., Navarro, M. O. P., Simionato, A. S., et al. (2019). Enhanced production of target bioactive metabolites produced by Pseudomonas aeruginosa LV strain. Biocatal. Agric. Biotechnol. 17, 653-664. doi: 10.1016/j.bcab.2019.01.025

Cardozo, V. F., Oliveira, A. G., Nishio, E. K., Perugini, M. R. E., Andrade, C. G. T. J., Silveira, W. D., et al. (2013). Antibacterial activity of extracellular compounds produced by a Pseudomonas strain against methicillin-resistant Staphylococcus aureus (MRSA) strains. Ann. Clin. Microbiol. Antimicrob. 12:12. doi: 10.1186/ 1476-0711-12-12

de Oliveira, A. G., Murate, L. S., Spago, F. R., Lopes, L. D. P., Beranger, J. P. D. O., Martin, J. A. B. S., et al. (2011). Evaluation of the antibiotic activity of extracellular compounds produced by the Pseudomonas strain against the Xanthomonas citri pv. citri 306 strain. Biol. Control 56, 125-131. doi: 10.1016/j. biocontrol.2010.10.008

de Oliveira, A. G., Spago, F. R., Simionato, A. S., Navarro, M. O. P., da Silva, C. S., Barazetti, A. R., et al. (2016). Bioactive organocopper compound from Pseudomonas aeruginosa inhibits the growth of Xanthomonas citri subsp. citri. Front. Microbiol. 7:113. doi: 10.3389/fmicb.2016.00113

Gionco, B., Tavares, E. R., de Oliveira, A. G., Yamada-Ogatta, S. F., do Carmo, A. O., Pereira, U. P., et al. (2017). New insights about antibiotic production by Pseudomonas aeruginosa: a gene expression analysis. Front. Chem. 5:66. doi: 10.3389/fchem.2017.00066

\section{DATA AVAILABILITY STATEMENT}

The datasets generated for this study are available on request to the corresponding author.

\section{AUTHOR CONTRIBUTIONS}

GA, HF, and MN conceived the study and designed the experimental procedures. $\mathrm{MN}, \mathrm{AS}, \mathrm{KG}, \mathrm{MD}, \mathrm{BC}, \mathrm{AB}$, and LA carried out the experiments. MN, AS, GD, AC, and GA analyzed the data. GD and $\mathrm{HF}$ contributed reagents and materials. $\mathrm{MN}, \mathrm{GA}, \mathrm{HF}$, and $\mathrm{AC}$ wrote this manuscript. GA supervised the project.

\section{FUNDING}

This work was supported by the Brazilian National Council for Scientific and Technological Development (CNPq) and Coordination for the Improvement of Higher Education Personnel (CAPES, Brazil) and Araucaria Foundation. This work was also funded by São Paulo Research Foundation, FAPESP 2017/50216-0 to HF.

\section{ACKNOWLEDGMENTS}

We would like to thank the Laboratory of Spectroscopy ESPEC UEL/FINEP for the help with the NMR, X-ray, and infrared analysis; Laboratory for Electron Microscopy and Microanalysis - LMEM UEL/FINEP for the help with the electron microscopy experiments; and UEL Central Animal Facility for providing the mice.

Itoh, S., Inuzuka, K., and Suzuki, T. (1970). New antibiotics produced by bacteria grown on n-paraffin (mixture of C12. C 13 and C14 fractions). J. Antibiot. 23, 542-545. doi: 10.7164/antibiotics.23.542

Kapuscinski, J. (1995). DAPI: a DNA-Specific fluorescent probe. Biotech. Histochem. 70, 220-233. doi: 10.3109/10520299509108199

Kerbauy, G., Vivan, A. C., Simões, G. C., Simionato, A. S., Pelisson, M., Vespero, E. C., et al. (2016). Effect of a metalloantibiotic produced by Pseudomonas aeruginosa on Klebsiella pneumoniae Carbapenemase (KPC)producing K. pneumoniae. Curr. Pharm. Biotechnol. 17, 389-397. doi: 10.2174/ 138920101704160215171649

Król, E., de Sousa Borges, A., da Silva, I., Polaquini, C. R., Regasini, L. O., Ferreira, H., et al. (2015). Antibacterial activity of alkyl gallates is a combination of direct targeting of FtsZ and permeabilization of bacterial membranes. Front. Microbiol. 6:390. doi: 10.3389/fmicb.2015.00390

Lopes, L. P., Oliveira, A. G. Jr., Beranger, J. P. O., Góis, C. G., Vasconcellos, F. C. S., San Martin, J. A. B., et al. (2012). Activity of extracellular compounds of Pseudomonas sp. against Xanthomonas axonopodis in vitro and bacterial leaf blight in eucalyptus. Trop. Plant Pathol. 37, 233-238. doi: 10.1590/S198256762012000400001

Ma, L.-S., Jiang, C.-Y., Cui, M., Lu, R., Liu, S.-S., Zheng, B.-B., et al. (2013). Fluopsin $\mathrm{C}$ induces oncosis of human breast adenocarcinoma cells. Acta Pharmacol. Sin. 34, 1093-1100. doi: 10.1038/aps.2013.44

Martins, P. M., Lau, I. F., Bacci, M., Belasque, J., do Amaral, A. M., Taboga, S. R., et al. (2010). Subcellular localization of proteins labeled with GFP in 
Xanthomonas citri ssp. citri: targeting the division septum. FEMS Microbiol. Lett. 310, 76-83. doi: 10.1111/j.1574-6968.2010.02047.x

Munhoz, L. D., Fonteque, J. P., Santos, I. M. O., Navarro, M. O. P., Simionato, A. S., Goya, E. T., et al. (2017). Control of bacterial stem rot on tomato by extracellular bioactive compounds produced by Pseudomonas aeruginosa LV strain. Cogent Food Agric. 3, 1-16. doi: 10.1080/23311932.2017.1282592

Murate, L. S., de Oliveira, A. G., Higashi, A. Y., Barazetti, A. R., Simionato, A. S., da Silva, C. S., et al. (2015). Activity of secondary bacterial metabolites in the control of citrus canker. Agric. Sci. 06, 295-303. doi: 10.4236/as.2015.63030

Navarro, M. O. P., Simionato, A. S., Pérez, J. C. B., Barazetti, A. R., Emiliano, J., Niekawa, E. T. G., et al. (2019). Fluopsin C for Treating MultidrugResistant Infections: In vitro Activity against clinically important strains and in vivo efficacy against carbapenemase-producing Klebsiella pneumoniae. Front. Microbiol. 10:2431. doi: 10.3389/fmicb.2019.02431

Otsuka, H., Niwayama, S., Tanaka, H., Take, T., and Uchiyama, T. (1972). An antitumor antibiotic, no. 4601 from Streptomyces, identical with YC 73 of Pseudomonas origin. J. Antibiot. 25, 369-370. doi: 10.7164/antibiotics.25.369

Savietto, A., Polaquini, C. R., Kopacz, M., Scheffers, D. J., Marques, B. C., Regasini, L. O., et al. (2018). Antibacterial activity of monoacetylated alkyl gallates against Xanthomonas citri subsp. citri. Arch. Microbiol. 200, 929-937. doi: 10.1007/ s00203-018-1502-6

Schaad, N. W., Postnikova, E., Lacy, G., Sechler, A., Agarkova, I., Stromberg, P. E., et al. (2006). Emended classification of xanthomonad pathogens on citrus. Syst. Appl. Microbiol. 29, 690-695. doi: 10.1016/j.syapm.2006.08.001
Sekhon, B. S. (2010). Metalloantibiotics and antibiotic mimics - an overview. J. Pharm. Educ. Res. 1, 1-20.

Strahl, H., and Hamoen, L. W. (2010). Membrane potential is important for bacterial cell division. Proc. Natl. Acad. Sci. U.S.A. 107, 12281-12286. doi: 10.1073/pnas.1005485107

Sumares, J. A., Morao, L. G., Martins, P. M., Martins, D. A., Gomes, E., Belasque, J., et al. (2016). Temperature stress promotes cell division arrest in Xanthomonas citri subsp. citri. Microbiol. Open 5, 244-253. doi: 10.1002/mbo3.323

Vasconcellos, F. C. S., de Oliveira, A. G., Lopes-Santos, L., Beranger, J. P. O., Cely, M. V. T., Simionato, A. S., et al. (2014). Evaluation of antibiotic activity produced by Pseudomonas aeruginosa LV strain against Xanthomonas arboricola pv. pruni. Agric. Sci. 05, 71-76. doi: 10.4236/as.2014.51008

Conflict of Interest: The authors declare that the research was conducted in the absence of any commercial or financial relationships that could be construed as a potential conflict of interest.

Copyright $(2020$ Navarro, Dilarri, Simionato, Grzegorczyk, Dealis, Cano, Barazetti, Afonso, Chryssafidis, Ferreira and Andrade. This is an open-access article distributed under the terms of the Creative Commons Attribution License (CC BY). The use, distribution or reproduction in other forums is permitted, provided the original author(s) and the copyright owner(s) are credited and that the original publication in this journal is cited, in accordance with accepted academic practice. No use, distribution or reproduction is permitted which does not comply with these terms. 